\title{
RENTABILIDADE NA TERMINAÇÃO DE BOVINOS DE CORTE EM CONFINAMENTO: UM ESTTUDO DE CASO EM 2003, NA REGIÃO OESTE DE MINAS GERAIS
}

\author{
Profitability analysis of the finishing of beef cattle in \\ feedlot: a study of case in 2003, in west region of \\ Minas Gerais State, Brazil
}

Marcos Aurélio Lopes ${ }^{1}$, Gustavo Pires Magalhães ${ }^{2}$

\begin{abstract}
RESUMO
Este trabalho teve como objetivo analisar a rentabilidade da terminação de bovinos de corte em confinamento e identificar os componentes que exerceram maior influência sobre os custos finais da atividade. Os dados analisados foram provenientes de um confinamento de bovinos de corte localizado no oeste do Estado de Minas Gerais, no qual foram terminados, em confinamento, 4.516 animais, durante os meses de abril a dezembro de 2003. O processamento eletrônico dos dados foi realizado utilizando uma planilha eletrônica. Os itens componentes do custo operacional efetivo que exerceram maior influência sobre os custos da atividade foram, em ordem decrescente: aquisição de animais, alimentação, despesas diversas, mão-de-obra, sanidade e impostos fixos. O confinamento do sistema de produção em estudo obteve um resultado final positivo, evidenciando que a atividade tem condições de sobreviver no longo prazo, inclusive se capitalizando.
\end{abstract}

Termos para indexação: Análise de rentabilidade, custo de produção, pecuária de corte.

\section{ABSTRACT}

The objectives of this research were to analyze the profitability of finishing beef cattle in feedlot, and to identify the components that had a greater influence upon the final costs of the activity. Data were analyzed from a production system of beef cattle located in the West of Minas Gerais state, Brazil, in which 4,516 animals were confined from April to December 2003. The electronic data processing as well as the profitability analysis of the production system were made by the electronic spreadsheet (Microsoft Excel). The component items of the effective operational cost that had a greater influence on the costs of the feedlot business were in decreasing order, the purchase of the animals, feeding, different expenses, labor, health and taxes. The feedlot of the production system under study reached a positive final result, pointing out the business has conditions to go on in a long term, and to capitalize.

Index terms: economical analysis, beef cattle, production cost.

Recebido para publicação em 10 de janeiro de 2005 e aprovado em 27 de maio de 2005

\section{INTRODUÇÃO}

A bovinocultura é uma importante atividade econômica para o Brasil, que de acordo com o ANUALPEC (2004) possui 195.551.576 cabeças de animais. Lopes \& Sampaio (1999) salientaram que existe uma preocupação, por parte dos pecuaristas, em explorar mais intensivamente suas propriedades, os quais têm buscado maiores produtividades e lucratividades. Esses mesmos pesquisadores mencionaram um crescimento de $110 \%$ no número de animais confinados durante o período de 1990 a 1997. De acordo com o ANUALPEC (2004), o número de animais confinados, durante o período de 1995 a 2003, cresceu $61,8 \%$.

A pecuária de corte, nos últimos anos, tem valorizado o planejamento, o controle, a gestão produtiva e empresarial das fazendas (LACORTE, 2002). Segundo Antonialli (1998), administrar uma empresa rural resume-se em exercer as funções de planejar, organizar, dirigir e controlar os esforços de um grupo de pessoas, visando atingir objetivos previamente determinados que podem ser a sobrevivência, crescimento, o lucro, o prestígio ou o prejuízo.

De acordo com Nogueira (2004), o produtor deve profissionalizar-se por completo, ou seja, deve adotar todas as técnicas e procedimentos modernos de modo que produza com eficiência, buscando escala e redução de custos. De acordo com Lopes \& Carvalho (2002), a necessidade de analisar economicamente a atividade gado de corte é extremamente importante, pois, por meio dela, o produtor passa a conhecer com detalhes e a utilizar, de maneira inteligente e econômica, os fatores de produção.

${ }^{1}$ Professor do Departamento de Medicina Veterinária da Universidade Federal de Lavras/UFLA - DSc. - Cx. P. 3037 - $37200-000$ - Lavras, MG malopes@ufla.br

${ }^{2}$ Acadêmico do curso de Zootecnia da Universidade Federal de Lavras - gupima@yahoo.com.br 
A partir daí, localiza os pontos de estrangulamento, para depois concentrar esforços gerenciais e tecnológicos, para obter sucesso na sua atividade e atingir os seus objetivos de maximização de lucros ou minimização de custos.

Vários pesquisadores têm se preocupado em estudar diferentes aspectos da terminação de bovinos de corte em confinamento, tais como a nutrição (alimentos alternativos), instalações, tipos raciais, sexo e idade dos animais. Entretanto, poucos estudos têm sido realizados sobre a viabilidade econômica dessa atividade e são raros os pesquisadores que mostraram quais componentes exerceram maior influência sobre o custo de produção e nem mesmo identificaram o ponto de equilíbrio dos sistemas de produção.

Este estudo teve como objetivo analisar a rentabilidade da terminação de bovinos de corte em confinamento, no ano de 2003. Pretendeu-se ainda identificar os componentes que exerceram maior influência sobre o custo de produção, bem como identificar o ponto de equilíbrio.

\section{MATERIAIS E MÉTODOS}

Os dados analisados foram provenientes de um confinamento de bovinos de corte realizado durante os meses de abril a dezembro de 2003, localizado na região oeste do Estado de Minas Gerais. Para a análise de rentabilidade foi utilizada uma planilha eletrônica desenvolvida no MS Excell.

Para o estudo da análise de rentabilidade foram coletadas todas as despesas operacionais referentes à engorda dos animais, todas as receitas e inventariados os bens utilizados no confinamento. $\mathrm{O}$ ciclo de engorda foi de aproximadamente 100 dias, de modo que nesse período, obteve-se três ciclos, totalizando 4.516 animais.

Foi fornecida uma dieta total constituída de $56 \%$ de concentrado (Tabela 1) e 44\% de volumoso, sendo silagem de capim-elefante (Pennisetum purpureum, Schum), milho (Zea mays, L.) e cana-de-açúcar (Sacharum oficcinarum, Linn). A dieta foi distribuída aos animais quatro vezes por dia, utilizando uma misturadora alimentadora vertical Casale, com capacidade de $13 \mathrm{~m}^{3}$, acoplada a um trator Valmet 985 . Uma pá carregadeira Michigam Clark 75 foi utilizada no processo de desensilagem e abastecimento da alimentadora vertical. Os minerais foram fornecidos na própria dieta total. $\mathrm{O}$ sal comum foi fornecido à vontade em cochos dentro dos currais de engorda. No período de arroçoamento foram gastos 7.966 toneladas de volumoso e 2.801 toneladas de concentrado, sendo o consumo médio diário de 19,60 kg de volumoso e $6,89 \mathrm{~kg}$ de concentrado por animal, na matéria natural.

TABELA 1 - Composição do concentrado fornecido aos animais durante o confinamento (na matéria natural).

\begin{tabular}{lc}
\hline \multicolumn{1}{c}{ Ingredientes } & \% \\
\hline Quirela de milho & 30 \\
Refinazil & 20 \\
Farelo de arroz & 20 \\
Farelo de girassol & 15 \\
Raspa de mandioca & 9 \\
Confinamix & 2,5 \\
Calcáreo & 1,5 \\
Uréia & 2 \\
\hline Total & 100 \\
\hline
\end{tabular}

Os animais, basicamente da raça nelore e cruzados ( $1 / 2$ holandês e $1 / 2$ zebu), ao entrarem no confinamento, pesavam em média $357 \mathrm{~kg}$. Apenas os animais cruzados foram castrados, enquanto todos os animais foram vermifugados e vacinados contra raiva, aftosa, gangrena gasosa e carbúnculo sintomático. Após 45 dias, receberam uma dosagem de modificador orgânico e foram novamente pesados. Após a pesagem foram separados quanto a uma melhor uniformidade do peso e remanejados aos currais de engorda agrupando-se os animais com peso semelhantes, objetivando a formação de lotes mais homogêneos.

Os currais de engorda foram de terra batida compactada, com 12 divisões, sendo 4 de $1800 \mathrm{~m}^{2}, 4$ de 900 $\mathrm{m}^{2}$ e 4 de $680 \mathrm{~m}^{2}$, numa área total de $13.520 \mathrm{~m}^{2}$ e 430 metros lineares de cocho de concreto. Foi constatado aproximadamente $6,76 \mathrm{~m}^{2}$ de área por animal e um comprimento de cocho de $0,21 \mathrm{~m} /$ cabeça nos currais de engorda. Nesses currais estavam presentes bebedouros controlados por bóia.

O curral de manejo com área de $900 \mathrm{~m}^{2}$ era constituído de brete, balança mecânica e tronco de contenção, sendo todos cobertos, além de embarcadouro e currais de apartação. É delimitado por cerca composta de mourões de aroeira espaçados de $2 \mathrm{em} 2 \mathrm{~m}$ e unidos por 5 tábuas horizontais de $0,25 \mathrm{~m}$ de largura espaçadas de $0,25 \mathrm{~m}$, com uma altura total de $2,5 \mathrm{~m}$.

Os cálculos do custo de produção do gado de corte contemplaram as duas estruturas de custo de produção: Custo Total de Produção (clássica), que envolve o custo fixo (inclusive depreciação de benfeitorias, máquinas e

Ciênc. agrotec., Lavras, v. 29, n. 5, p. 1039-1044, set./out., 2005 
equipamentos) e variável utilizada por Barros (1948) e Custo Operacional, proposta por Matsunaga et al. (1976) e adotada pelo Instituto de Economia Agrícola - IEA/SP (MATSUNAGA et al., 1976). A metodologia utilizada nos cálculos da Margem Bruta, Margem Líquida e ponto de equilíbrio foi a adotada por Reis (1986). A depreciação foi calculada pelo método linear (HOFFMANN et al., 1981).

Os itens que compõem o Custo Operacional Efetivo de produção do gado de corte foram divididos em sete grupos: mão-de-obra, alimentação, sanidade, reprodução, aquisição de animais, impostos e despesas diversas (LOPES et al., 1999).

\section{RESULTADOS E DISCUSSÃO}

Na Tabela 2 encontra-se um resumo da análise de rentabilidade da terminação de bovinos de corte em confinamento. Observa-se pelos indicadores de eficiência econômica margem bruta, líquida e "resultado" que a atividade teve viabilidade econômica. A margem bruta, que são as receitas menos o custo operacional efetivo, foi de $\mathrm{R} \$ 166.586,57$. Tal resultado mostra que a atividade está se remunerando. A margem líquida, que é a receita menos o custo operacional total, foi de $\mathrm{R} \$ 144.928,49$, mostrando que a atividade é estável, com possibilidade de expansão ou de se manter a médio prazo (LOPES \& CARVALHO, 2002). O "resultado", que é a diferença entre as receitas e o custo total (custos fixos e custos variáveis), teve um valor de R \$ 9.120,70. Sendo o "resultado" positivo, atividade foi lucrativa, o que, de acordo com Lopes \& Carvalho (2002), significa que ela se manterá a longo prazo, possibilitando a capitalização do empresário.

As despesas operacionais, que referem-se aos gastos com alimentação, aquisição de animais, impostos fixos, mão-de-obra, sanidade e despesas diversas da atividade, totalizaram $\mathrm{R} \$ 3.812 .856,31$. Com alimentação (aquisição de grãos, farelos, volumosos e minerais), houve um gasto de $\mathrm{R} \$ 1.159 .822,97$, representando $30,25 \%$ do total das despesas. No grupo alimentação, o gasto com volumoso representou $18,78 \%$ e as despesas com concentrado $81,22 \%$. A aquisição de 4.516 animais totalizou $\mathrm{R} \$ 2.552 .723,70$, representando $66,57 \%$. Os gastos com impostos, referentes a ITR e IPVA, somaram R\$ 1.662,19, representando $0,04 \%$. A mão-de-obra dos funcionários do confinamento e do escritório totalizaram $\mathrm{R} \$ 25.464,00$, representando $0,66 \%$. As despesas com sanidade (vacinas, vermífugos, modificador orgânico e outros) foram de R\$ $8.289,50$, representando $0,22 \%$, evidenciando que não justifica, em hipóte se alguma, deixar de vacinar e nem mesmo realizar o controle de parasitas, cujos prejuízos decorrentes da presença dessas doenças influenciarão significativamente na rentabilidade. As despesas diversas (óleo diesel, energia elétrica, manutenção de máquinas e frete dos animais) totalizaram $\mathrm{R} \$ 64.893,95$, constituindo $1,69 \%$ das despesas operacionais efetivas. O custo total foi de $\mathrm{R} \$ 3.970 .322,18$ (Tabela 2).

Quanto aos componentes do custo de produção que exerceram maior influência sobre os custos finais da atividade, os resultados obtidos no confinamento estudado, referentes às despesas com aquisição de animais, alimentação (Tabela 3), foram semelhantes aos obtidos por Lopes \& Sampaio (1999). Já as despesas com mão-de-obra e sanidade foram inferiores, enquanto que as despesas diversas do confinamento em estudo foram bem superiores aos percentuais encontrados por esses mesmos pesquisadores. A aquisição dos animais, que representou $66,57 \%$ do total das despesas operacionais efetivas, mostra que os pecuaristas devem dar uma atenção especial nesse quesito, pois uma pequena economia, sem deixar de lado a qualidade dos animais a serem confinados, representa uma redução considerável do custo operacional efetivo, que refletirá na lucratividade e na rentabilidade. A divisão das despesas em grupos, de acordo com Lopes et al. (1999) permite o monitoramento das despesas do sistema de produção de gado de corte, auxiliando o técnico e o produtor em uma análise mais detalhada, possibilitando detectar mais facilmente os pontos de estrangulamento.

A receita total foi de $\mathrm{R} \$ 3.979 .442,88$, referente à venda dos 4.516 bovinos pesando $70.787,45$ arrobas a um preço médio de R\$56,22/arroba, bem como a venda do esterco. Os animais foram vendidos com uma média de 15,67 arrobas, obtendo um ganho médio de 3,75 arrobas no período de engorda e um rendimento de carcaça médio de 51,15\%.

De acordo com Lopes \& Sampaio (1999), a receita proveniente da venda de esterco constitui cerca de $6,78 \%$ (Tabela 3). No confinamento estudado, o percentual encontrado foi de $0,53 \%$, pois grande parte desse subproduto foi utilizado como adubo orgânico nas capineiras. De acordo com Lopes et al. (2004), o fato do esterco ter sido utilizado no próprio sistema de produção, embora, em um primeiro momento signifique possível redução da receita, representou também uma redução nas despesas com manutenção das capineiras.

O custo fixo, representado pela remuneração da terra, remuneração sobre o capital investido, custo com depreciação e custo com impostos (ITR e IPVA), representou $1,13 \%$ em relação ao custo total, enquanto que o custo variável, representado pelo custo operacional efetivo sem impostos e remuneração sobre o capital de giro, foi de $98,87 \%$, em relação ao custo total. 
TABELA 2 - Resumo da análise de rentabilidade da terminação de bovinos de corte em confinamento.

\begin{tabular}{|c|c|}
\hline Discriminação & Resultados \\
\hline Receitas & $\mathrm{R} \$ 3.979 .442,88$ \\
\hline Custo Operacional Total & $\mathrm{R} \$ 3.834 .514,39$ \\
\hline Custo Operacional Efetivo (despesas) & $\mathrm{R} \$ 3.812 .856,31$ \\
\hline Custo com Depreciação & $\mathrm{R} \$ 21.658,08$ \\
\hline Custo Total & $\mathrm{R} \$ 3.970 .322,18$ \\
\hline Custos Fixos & $\mathrm{R} \$ 44.742,37$ \\
\hline - Remuneração da terra & $\mathrm{R} \$ 6.000,00$ \\
\hline - Remuneração sobre o capital investido & $\mathrm{R} \$ 15.422,10$ \\
\hline - Custo com depreciação & $\mathrm{R} \$ 21.658,08$ \\
\hline - Custo com impostos & $\mathrm{R} \$ 1.662,19$ \\
\hline Custos Variáveis & $\mathrm{R} \$ 3.925 .579,81$ \\
\hline - Custo operacional efetivo sem impostos & $\mathrm{R} \$ 3.811 .194,12$ \\
\hline - Remuneração sobre o capital de giro & $\mathrm{R} \$ 114.385,69$ \\
\hline Margem Bruta & $\mathrm{R} \$ 166.586,57$ \\
\hline Margem Líquida & $\mathrm{R} \$ 144.928,49$ \\
\hline Resultado & $\mathrm{R} \$ 9.120,70$ \\
\hline Custo Operacional Efetivo / @ & $\mathrm{R} \$ 53,86$ \\
\hline Custo Operacional Total / @ & $\mathrm{R} \$ 54,17$ \\
\hline Custo Total / @ & $\mathrm{R} \$ 56,09$ \\
\hline Custo Variável Unitário / @ & $\mathrm{R} \$ 55,46$ \\
\hline Preço Médio da @ & $\mathrm{R} \$ 56,22$ \\
\hline Produção Total & 70.787,45@ \\
\hline Ponto de Equilíbrio & $58.800,93$ \\
\hline Lucratividade & $0,23 \%$ \\
\hline Rentabilidade & $11,09 \%$ \\
\hline Custo Fixo / Custo Total & $1,13 \%$ \\
\hline Custo Variável / Custo Total & $98,87 \%$ \\
\hline Custo com Depreciação / Custo Operacional Total & $0,56 \%$ \\
\hline Custo Operacional Efetivo / Custo operacional Total & $99,44 \%$ \\
\hline
\end{tabular}

Ciênc. agrotec., Lavras, v. 29, n. 5, p. 1039-1044, set./out., 2005 
TABELA 3 - Influência dos componentes da receita e despesas operacionais efetivas da terminação de bovinos de corte em confinamento, comparado com outro estudo.

\begin{tabular}{lcc}
\hline Discriminação & Lopes \& Sampaio (1999) & Presente estudo \\
\hline Total das receitas & 100,00 & 100,00 \\
Receita com animais & 93,22 & 99,47 \\
Receita com esterco & 6,78 & 0,53 \\
\hline Total das despesas & 100,00 & 100,00 \\
Aquisição de animais & 67,87 & 66,57 \\
Alimentação & 29,84 & 30,25 \\
Mão-de-obra & 1,04 & 0,66 \\
Sanidade & 0,51 & 0,22 \\
Diversas & 0,74 & 1,69 \\
Impostos & $*$ & 0,04 \\
\hline
\end{tabular}

* Não estimado

A depreciação foi de $\mathrm{R} \$ 21.658,08$, sendo responsável por $0,56 \%$ do custo operacional total (COT) (Tabela 2). Lopes \& Sampaio (1999) verificaram que a depreciação foi responsável por 4,71; 2,72 e 1,65\% do custo operacional total, em confinamentos de 100, 500 e 1.000 cabeças, respectivamente. Embora na literatura não exista informação sobre qual seria um bom valor para esse indicador técnico, pode-se dizer que, a eficiência de utilização dos bens do patrimônio do sistema de produção estudado nesta pesquisa foi superior ao sistema estudado por esses pesquisadores.

$\mathrm{O}$ ponto de equilíbrio foi de 58.800 arrobas, enquanto que a produção total foi de 70.787 arrobas. O custo operacional efetivo/arroba foi de $\mathrm{R} \$ 53,86$ e o custo total/ arroba foi de $\mathrm{R} \$ 56,09$, enquanto o preço médio da arroba vendida foi de $\mathrm{R} \$ 56,22$ /arroba. A lucratividade, representada pelo lucro sobre a receita, foi de $0,23 \%$ e a rentabilidade foi de $11,09 \%$, permitindo comparar se a atividade é competitiva com outras formas de aplicação do capital como a poupança, por exemplo.

\section{CONCLUSÕES}

A atividade de confinamento de bovinos de corte desenvolvida no sistema de produção analisado apresentou viabilidade econômica, evidenciando que a atividade tem condições de sobreviver no longo prazo, inclusive se capitalizando.

Percentualmente, os itens componentes do custo operacional efetivo que exerceram maior influência sobre os custos do confinamento foram, em ordem decrescente: compra de animais, alimentação, despesas diversas, mãode-obra, sanidade e impostos fixos.

\section{REFERÊNCIAS BIBLIOGRÁFICAS}

ANTONIALLI, L. M. Contabilidade gerencial agropecuária. In: ENCONTRO DE ATUALIZAÇÃO TÉCNICA EM PECUÁRIA LEITEIRA, 3., 1998, Jaboticabal, SP. Anais... Jaboticabal: [s.n.], 1998. p. 1-17.

ANUALPEC. Anuário da pecuária brasileira. São Paulo: FNP, 2004. 385 p.

BARROS, H. Economia agrária. Lisboa: Sá da Costa, 1948.

HOFFMANN, R.; ENGLER, J. J. C.; SERRANO, O. Administração da empresa agrícola. 3. ed. São Paulo: Pioneira, $1981.325 \mathrm{p}$.

LACORTE, A. J. F. Principais aspectos do confinamento de gado de corte no Brasil. In: SIMPÓSIO DE PECUÁRIA DE CORTE: NOVOS CONCEITOS NA PRODUÇÃO BOVINA, 2., 2002, Lavras, MG. Anais... Lavras: UFLA, 2002. p. 81-107.

LOPES, M. A.; CARVALHO, F. de M. Custo de produção do gado de corte. Lavras: UFLA, 2002. 47 p. (Boletim Agropecuário, 47). 
LOPES, M. A.; JUNQUEIRA, L. V.; CARVALHO, F. M.; ZAMBALDE, A. L.; LOPES, D. de C. F. de. Desenvolvimento de um sistema computacional para determinação do custo de produção do gado de corte. Revista Brasileira de Agroinformática, [S.1.], v. 2, n. 2, p. 105-116, 1999.

LOPES, M. A.; LIMA, A. L. R.; CARVALHO, F. de M.; REIS, R. P.; SANTOS, I. C.; SARAIVA, F. H. Controle gerencial e estudo da rentabilidade de sistemas de produção de leite na região de Lavras (MG). Revista Ciência e Agrotecnologia, Lavras, v. 28, n. 4, p. 883892, 2004.
LOPES, M. A.; SAMPAIO, A. A. M. Manual do confinador de bovinos de corte. Jaboticabal: FUNEP, 1999. 106 p.

MATSUNAGA, M.; BEMELMANS, P. F.; TOLEDO, P. E. N. de. Metodologia de custo de produção utilizado pelo IEA. Agricultura em São Paulo, São Paulo, v. 23, n. 1, p. 123-139, 1976.

NOGUEIRA, M. P. Importância da gestão de custos: módulo 1. [S.1.]: Agripoint, 2004. p. 6.

REIS, D. L. dos. Estudo técnico e econômico da propriedade rural. Informe Agropecuário, Belo Horizonte, v. 12, n. 143, p. 23-38, 1986.

Ciênc. agrotec., Lavras, v. 29, n. 5, p. 1039-1044, set./out., 2005 